Original Research Paper

\title{
Something about the Balancing of Thermal Motors
}

\author{
${ }^{1}$ Raffaella Aversa, ${ }^{2}$ Relly Victoria V. Petrescu, \\ ${ }^{3}$ Bilal Akash, ${ }^{4}$ Ronald B. Bucinell, ${ }^{5}$ Juan M. Corchado, \\ ${ }^{6}$ Guanying Chen, ${ }^{7}$ Shuhui Li, ${ }^{1}$ Antonio Apicella and ${ }^{2}$ Florian Ion T. Petrescu \\ ${ }^{I}$ Advanced Material Lab, Department of Architecture and Industrial Design, \\ Second University of Naples, 81031 Aversa (CE), Italy \\ ${ }^{2}$ ARoTMM-IFToMM, Bucharest Polytechnic University, Bucharest, (CE), Romania \\ ${ }^{3}$ Dean of School of Graduate Studies and Research, American University of Ras Al Khaimah, UAE \\ ${ }^{4}$ Union College, USA \\ ${ }^{5}$ University of Salamanca, Spain \\ ${ }^{6}$ Harbin Institute of Technology and SUNY Buffalo, China \\ ${ }^{7}$ University of Alabama, USA
}

Article history

Received: 30-11-2016

Revised: 08-12-2016

Accepted: 15-03-2017

Corresponding Author:

Florian Ion T. Petrescu

ARoTMM-IFToMM,

Bucharest Polytechnic

University, Bucharest, (CE),

Romania

Email:scipub02@gmail.com

\begin{abstract}
Internal combustion engines in line (regardless of whether the work in four-stroke engines and two-stroke engines Otto cycle engines, diesel and Lenoir) are, in general, the most used. Their problem of balancing is extremely important for their operation is correct. There are two possible types of balancing: Static and dynamic balance. The total static to make sure that the sum of the forces of inertia of a mechanism to be zero. There are also a static balance partial. Dynamic balance means to cancel all the moments (load) inertia of the mechanism. A way of the design of an engine in a straight line is that the difference between the crank $180\left[^{\circ}\right]$ or $120\left[^{\circ}\right]$. A different type of construction of the engine is the engine with the cylinders in the opposite line, called "cylinder sportsmen". In this type of engine (regardless of their position, which is most often vertical) for engines with two cylinders, one has a static balance total and an imbalance in the dynamic. Similar to the model of the earth concentrated in rotation movement are resolved and load balancing shafts rotating parts. An important way to reduce losses of heat engines is how to achieve a better balance. The methods may be used in equal measure and on engines with external combustion, type Stirling or Watt.
\end{abstract}

Keywords: Kinematics, Forces, Balancing Motors, Main Mechanism, Engines, Heat Engines

\section{Introduction}

The term "combustion and explosion engine" refers to any type of internal combustion engine with reciprocating or rotary, diesel or spark-ignition internal combustion engines in which gases burn with a flame front whose speed is normally lower than that of sound.

This engine is mainly used for the propulsion of transport vehicles (such as airplanes, cars, motorcycles, trucks, boats) but also for many mobile tools such as chainsaws, lawn mowers and many fixed installations, Pumps, etc.).
An explosion or detonation is a particular form of combustion in which the velocity of the flame front is at least partly supersonic. In spark-ignition engines, detonation is a malfunction (rattling), normally it is a deflagration that occurs within these engines.

\section{Four-Stroke Spark-Ignition Engine}

These are all engines that use gasoline, alcohol, or even a gas (LPG, etc.) as fuel and whose combustion must be triggered by an external source of energy (candle, Shaker, breaker, Delco, etc.).

These motors convert the potential energy, chemical, stored in a fuel in work (mechanical energy) thanks to 
very rapid combustion, hence the term, unjustly used, of "explosion" (Four-stroke engine, From Wikipedia; Nikolaus Otto, From Wikipedia; Otto cycle, From Wikipedia; Otto engine, From Wikipedia).

They consist of one or more cylinders to confine the combustion and use energy. In each cylinder, a piston slides in an alternating rectilinear motion. This movement is transformed into rotation by means of a connecting rod connecting the piston to the crankshaft, an assembly of cranks on an axis.

\section{With Valves}

Each cylinder is closed by a cylinder head equipped with at least two valves: The first, the intake valve allows the supply of air/fuel mixture of the cylinder through the inlet manifold; the second, the exhaust valve allows the evacuation of burnt gases to the exhaust.

\section{Without Valves}

There were engines without valves, these being replaced by movable folders called "louvoyantes" discovering lights. This principle was used successfully (excellent reliability, very good efficiency, silence of operation) on Bristol aircraft engines which were built under license by Snecma until the 1970s, for the equipment of Noratlas military transport aircraft.

Two valveless engine systems were built, the Knight system, with two moving sleeves at the top and bottom in opposite direction for the outer and inner sleeves, which were installed on Willys, Daimler, Panhard, Voisin, Minerva, Peugeot and others and the BurtMcCollum-type single sleeve system with simultaneous up and down and right and left movement, any point of the sleeve made a kind of ellipse, did not have the serious problems of the Knight system and also eliminated the regions with high wear by low lubrication close to the PMS and PMI of the piston stroke.

According to an interview with Mike Hewland (Car and Driver, July 1974) he managed to rotate a $500 \mathrm{cc}$ single cylinder with distribution type, first installed on Argyll cars and later in the Bristol aviation engines, with a lower oil consumption than on engines with traditional valves and a specific gasoline consumption of around $175 \mathrm{~g} / \mathrm{hp}$, the engine also operated with creosote.

The more intensive efforts for the development of the Burt-McCollum system were made in England by $\mathrm{H}$. Ricardo and R. Fedden.

The Wankel engine is a rotary piston engine operating in the Beau de Rochas cycle, in which a "triangular" piston converts energy from fuel combustion into mechanical rotational energy.

\section{Operation}

The cycle of operation breaks down analytically into four stages or phases.
The movement of the piston is initiated by the combustion (rapid increase of the temperature and therefore of the gas pressure) of a mixture of fuel and air (oxidizer) which takes place during engine time.

It is the only time producing energy; the other three times consume but make it possible. The piston moves during start-up by an external power source (often a starter or launcher: An electric motor is temporarily coupled to the crankshaft) until at least one engine time produces a force capable of Three other times before the next engine time.

The motor then operates alone and generates torque on its output shaft.

The following is a description of the successive cycles of a four-stroke engine:

Inlet of a mixture of air and pulverized fuel, previously mixed and prepared by various components (carburettor or indirect injection system): Opening of the inlet and outlet valve (s), the latter Aspirates this mixture in the cylinder at a pressure of 100 to 300 mbar (nonsupercharged "atmospheric" engines) to about 2,500 mbar for a supercharged standard automobile engine (expressed as absolute pressure);

Compression of the mixture: Closure of the inlet valve and then raising of the piston which compresses the mixture to 30 bar and 400 to $500^{\circ} \mathrm{C}$ in the combustion chamber;

Combustion and expansion in the vicinity of Top Dead Center (TDC): Moment at which the piston reaches its peak and at which compression is at its maximum; the spark plug, connected to a high-voltage ignition system, produces a spark a few degrees before the TDC; the initiated combustion which follows constitutes the driving time; the hot gases at a pressure of 40 to 60 bar push the piston, initiating the movement;

Exhaust valve: Opening of the exhaust valve (s) and raising of the piston, which expels the exhaust gas in the exhaust manifold.

And a new cycle starts in 1.

\section{Diesel Four Stroke Engine}

Like the spark-ignition engine, the diesel engine consists of pistons sliding in cylinders, closed by a cylinder head connecting the cylinders to the intake and exhaust manifolds, the cylinder head equipped with valves controlled by one or more camshafts.

The operation is based on the self-ignition of diesel, heavy fuel oil or raw vegetable oil in compressed air at a compression ratio of more than 1:15 of the cylinder volume, the temperature of which is increased to about $600^{\circ} \mathrm{C}$. As soon as the fuel is injected (sprayed) into the compressed air, it ignites almost instantaneously, without the need for spark-ignition.

When burning, the mixture greatly increases the temperature and pressure (on the old Diesel the injection 
pressure was 130 to 200 bar, whereas in the modern common rail Diesel it can reach 2000 bar which promotes a more complete combustion and Less polluting), pushing back the piston which provides work on a connecting rod, which causes the crankshaft to rotate (or crank shaft acting as a motor shaft, see connecting rod-crank system).

The four-cycle diesel cycle includes:

- Admission of air through the opening of the intake valve (s) and the descent of the piston

- Compressing the air by raising the piston, the inlet valve (s) being closed

- Injection-combustion-expansion: Shortly before top dead center, the fuel is introduced by a high pressure injector to form an unstable mixture with the oxygen of the compressed air. The ensuing rapid combustion is engine time, hot gases in rapid expansion push the piston back, releasing some of their energy. This can be measured by the engine power curve

- Exhaust gases from the exhaust valve (s), which are pushed by the rising piston

The only spark plugs on a diesel engine are the "preheating" spark plugs which, as the name suggests, preheat the combustion chambers (or pre-chambers according to the type of diesel) in order to obtain, when the engine is cold, a sufficient temperature for selfignition of the fuel. This system also sometimes provides "post-heating" to ensure the rotational stability of the engine and the reduction of polluting emissions at low temperatures.

\section{Two-Stroke Engine}

The first two-stroke engine was designed and built by Étienne Lenoir in 1859. It used a lighting gas. It operates according to the Lenoir cycle. In its economical version with a simple carburetor, its efficiency is lower and it is more polluting, but with considerably higher power and torque ( 60 to $70 \%$ ) than a four-stroke engine.

Itself displaced at the same speed; it remained for a long time and still remains the exclusive and powerful motor of mopeds and some sports motorcycles replica of motorcycles of competition in GP and off-road. Since 1990, we are again interested in two-stroke engines for the automobile but in direct pneumatic injection, a solution increasingly used today on smalldisplacement two-wheelers and which meets the pollution standards Euro 3.

The two-stroke engines respect the Beau de Rochas cycle by using both sides of the piston: The upper part for the compression and combustion phases and the lower part to ensure the transfer of the intake gases (and by way of Consequently, escape).
They save the movement (thus latency, friction, etc.) of two non-energy-producing cycles and produce more torque and power.

Between the two existing sweeping systems for twostroke engines (the Schnürle system-or in a loop and the one-way flow called uniflux or "equicouring"), recent research has shown that the Loop is always better than the uniflux system (or equicourant).

The theoretical power of a 2 -stroke engine is twice that of a 4-stroke engine, but removing two strokes creates difficulties because it is necessary to expel the flue gases before admitting the air and this in a very short time.

The exhaust and intake must be carried out simultaneously in the vicinity of the PMB with the obligatory rescue of an air pressure higher than the atmospheric pressure supplied either by a coupled sweeping pump (alternative or rotary) or by a turboblower; 30 to $40 \%$ of the energy generated by the driving stroke is absorbed by the coupled scanning pumps; hence the use of turbo-blowers (TS) which use exhaust gas energy, which improves the overall efficiency.

Two-stroke engines allow theoretically to benefit from double duty per cycle (one engine cycle per crankshaft revolution, instead of one engine cycle for two crankshaft turns for the four stroke engine). However, waterproofing remains difficult to ensure and certain effects related to the location of the gas transfer channels (intake and exhaust) limit the practical gain to $70 \%$ of the work.

The main advantages of these engines include:

- A combustion at each engine revolution and a very high power (capacity/displacement), hence a very high mass power

- A simplicity of construction (few moving parts)

- Lubricating the rotating elements regardless of the inclination of the engine

- Internal friction losses considerably lower than on a 4-stroke (crankshaft on bearings, no distributing to be driven, no scraper segment, much lower system at the equivalent power supplied)

- A very expressive motor character, which works better and better when approaching its maximum speed. The opposite of the four times that seems to force and want to eject its components in this case

- With equal power, a reliability superior to the 4stroke that must run much faster, which is highlighted by comparing the NR500 Honda Grand Prix from the $1980 \mathrm{~s}$ to the 500 2-strokes of the time

- A lower heat transfer to the engine cooling system compared to the four-stroke engines, thus a better efficiency from the point of view of the thermodynamic cycle 


\section{Diesel Two Stroke}

However, two-stroke engines still have great potential in specific sectors, for example the very high powers (marine propulsion or electric power generation) where two-stroke diesel engines called "slow engines" deliver more than $100,000 \mathrm{hp}$ with a $50 \%$.

These are engines with five to fourteen cylinders in line with a piston diameter of $1 \mathrm{~m}$ and a stroke of $2.50 \mathrm{~m}$.

The speed of rotation of their shaft is about 100 revolutions per minute. Their main qualities are reliability and low consumption. On the other hand, their height (about $17 \mathrm{~m}$ ) and their mass (more than 1000 tons) limit their use.

Four-stroke engines of equivalent power are about three times lighter and less expensive, at the cost of a drop in efficiency of about 3\% and less durability. Some of these two-stroke engines used in electric generation have lasted more than fifty years.

Some aircraft engines also use this principle, quite old, since already used by the Clerget engines of the 1930 s. Today, the best known is the Wilksch engine, a twin-stroke 120-hp supercharged by compressor. There are also in 2 and 4-cylinder, as well as the promising prototype undergoing the Zoche star engine certification (300 hp).

The advantage in this case of the two-stroke diesel engine is a weight/power ratio equivalent to a 4-stroke gasoline, but with better efficiency and the use of a fuel three times cheaper, kerosene, instead of Costly and polluting aviation gasoline to lead.

\section{Yield}

The efficiency of an engine is the ratio between the delivered mechanical power and the thermal power supplied by the fuel. It depends on the thermodynamic cycle chosen, the operating parameters (compression ratio) and the thermal, mechanical (friction), flow (intake and exhaust) losses as well as losses due to the accessories necessary for its operation Such as injection pump (diesel engine), cooling fan, cooling pump, oil pump, alternator, air conditioning compressor and other accessories.

The maximum efficiency for modern automotive engines is about $35 \%$ for ignition engines and $45 \%$ for diesel engines, while the largest industrial engines exceed $50 \%$.

The energy necessarily lost following the Carnot cycle can be recovered by cogeneration (to reheat another fluid such as domestic hot water), significantly improving the overall energy balance of the installation as a whole.

In the case of an automobile engine that rarely operates at high loads and always in a transient manner, the actual practical output is much lower.

To drive at a steady speed of $120 \mathrm{~km} \mathrm{~h}^{-1}$, most cars need little more than $20 \mathrm{~kW}$, while engines can often provide three to eight times more, which leads to a very degraded practical performance.

Due to the additional transmission losses, idle engine, idle times, the actual practical performance of a car does not exceed $12 \%$.

\section{Alternative Architectures}

The defects of the conventional internal combustion engine are: Its poor efficiency, its vibrations and its level of pollution.

Many (distinct engines) architecture were born during the course of history, many remained in the form of drawings or models, some gave functional prototypes and a few architectures were entitled to industrial production.

The best known, used especially in automobiles, is that of the rotary piston engine, the Wankel engine, used by Citroën and NSU and then perfected by Mazda. There is also the Atkinson cycle architecture, used by Toyota in its hybrid vehicles marketed since 1997.

An equally original architecture, in the prototype state, is that of the quasiturbine. For the time being, no manufacturer seems to want to dethrone the reciprocating engine with its crankshaft and valves. The UK company ILMOR has developed a 5-stroke, dualexpansion engine to make better use of the energy that is lost in the exhaust. Otto himself had built something similar in the nineteenth century, but without success.

\section{Characterization}

The cubic capacity of an engine is the total volume (all cylinders) displaced during one cycle. It is calculated from the diameter of a cylinder (the bore), the distance traveled by a piston (stroke) and the number of cylinders.

The power developed by a motor is often represented by a motor power curve. It must be measured according to certain standards defining in particular the accessories used and the temperature and pressure conditions. It is always superior to the power actually available to the wheels for a vehicle because of the losses in the transmission. The legal unit used is $\mathrm{kW}$ but often attached to horsepower (ch) for historical reasons.

It is "low-speed torque" that makes it possible to accelerate a vehicle without having to "raise the engine speed", but it is the maximum power that determines the speed that this vehicle can reach. The gearbox makes it possible to increase the torque on the driving wheels while reducing the engine speed and conversely, depending on the objective pursued (acceleration/fuel economy).

The maximum torque exerted on the shaft. The legal unit used is $\mathrm{N} \cdot \mathrm{m}$ (although $\mathrm{kg} \cdot \mathrm{m}$ remains current). The power is the product of the torque by the speed of rotation (to obtain watts, it is necessary to multiply the torque in $\mathrm{N} \times \mathrm{m}$ by the speed of rotation in radians per second omega.). 
The compression ratio of a motor expresses the ratio between the volume left free in one of its cylinders between the bottom dead center and the top dead center. The higher it is the more the mixture is compressed so the explosion will be strong, therefore difficult to manage (mechanical shock, temperature...) but the higher the efficiency of the engine will be.

The maximum speed of rotation is generally expressed in revolutions per minute. It corresponds to the speed of rotation that the motor can reach when accelerating to the maximum. It is possible to increase this maximum speed of rotation with a motor preparation but be aware that the faster the engine runs, the more it wears out (the Formula 1 engines of the $2000 \mathrm{~s}$ reach $19,500 \mathrm{rpm}$ (like the RS26 engine of Renault In 2006) but need to be revised, or even replaced, frequently.

Also, with the increase in engine speed, the internal friction losses increase with the cube of the latter; this results in a degradation of the overall efficiency of the engine with the increase in engine speed.

The specific power expresses the power produced as a function of the cubic capacity (volume of gas contained after the intake cycle).

It is often expressed in relation to the liter of displacement. An engine of $500 \mathrm{~cm}^{3}$ developing $33 \mathrm{hp}$ thus has a "power output" of $66 \mathrm{hp} / \mathrm{L}$ while a $3000 \mathrm{~cm}^{3}$ developing $120 \mathrm{hp}$ offers only $40 \mathrm{hp}$.

The increase in the specific power is all the more the cylinder capacity decreases (thus the number of cylinders increases) since the power increases with the speed.

However, a motor of high unit displacement operating rapidly develops moments putting the assembly, in particular the piston, to a severe test and, therefore threatens its reliability.

As previously described, the norm is to speak of power per liter, but it is sometimes more advantageous to speak of power per liter per $1000 \mathrm{rpm}$ (defined here as $\mathrm{Plm}$ ) in order to have a more precise idea of the work Made on the engine.

Doing the calculation gives the level of development of an engine. One finds engines of series providing $\mathrm{Plm}$ of much less than $15 \mathrm{hp}$ (engine without supercharging).

The configuration of some engines will not allow to reach this level of performance even with modifications. For engines with two atmospheric valves, often the limit is about $13 \mathrm{hp} /$ liter/1,000 rpm.

The limit of power that an engine can obtain depends on its configuration, displacement and engine speed. Experience shows, however, that for an atmospheric engine, the power limit Plm is around $16 \mathrm{hp} / \mathrm{liter} / 1,000$ $\mathrm{rpm}$, but often $15 \mathrm{hp} / \mathrm{liter} / 1,000 \mathrm{rpm}$ at maximum $\mathrm{rpm}$ is achieved for an atmospheric engine.

Here are some examples:
- A 1-liter engine rotating at 12,000 rpm can develop $180 \mathrm{hp}$ (motor of some sports motorcycles of the years 2010)

- A 3-liter engine running at 18,000 rpm can develop $810 \mathrm{hp}$ (Formula 1 engine)

- This is true regardless of engine displacement, bore and stroke

Mass power is a ratio between the developed power and the mass of the engine. In the case of a stationary engine, it usually does not express anything useful, but aircraft manufacturers give it a great deal of importance.

The average pressure indicated represents the quality of the combustion and the tightness of the engine.

The average effective pressure is an image of the specific power. This is the product of the pmi by the yield.

\section{Cooling}

The repeated combustion overheats the parts in contact (piston, cylinder, valve) and diffuse by conduction on all mechanical parts of the engine. They must therefore be cooled under pain of destruction. For proper operation, internal combustion engines require a stabilized and adapted temperature.

\section{Air Cooling}

In 1875 the French Alexis de Bischop uses air for cooling. Its uncompressed, mixed-type engine has a cylinder surrounded by metal fins that increase the area in contact with air. This type of cooling is mainly used for low-power motors, such as mopeds and smalldisplacement motorcycles, but also on cars, such as some Porsche, GS, 2 CV or Ladybird and Panhard PL 17. Air cooled is also the majority for piston engines on aircraft. Air cooling has long been the benchmark for motorcycle engines (although there have always been motorcycles with liquid-cooled engines), but the problems caused by the high efficiency of these engines (breakage, premature wear) have led to The quasigeneralization of liquid cooling despite the specific advantages for the motorcycle of air cooling (bulk, weight, simplicity, price).

It can be optimized by the use of a fan whose presence does not always reveal an air cooling because it sometimes dissipates heat from the radiator of a liquid cooling system. Air cooling is better suited to extreme ambient temperatures, very hot or below zero, but above all in aeronautical use where they have caused some problems due to excessively high and rapid cooling in certain situations (shock cooling). The advantage for air-cooled engines for aeronautics is the lightness of the construction and its simplicity. Reciprocating engines on airplanes are equipped with a double lighted ignition with two spark plugs per cylinder, such as the Continental O-200 or Rolls-Royce O-200 
(identical) engine that equips the most widespread World: The Cessna 150/152.

\section{Liquid Cooling}

It is the Englishman Samuel Brown who invents the cooling of the engine by water in order to improve the performances of the cooling. In its motor, the water driven by a pump circulates around the cylinders surrounded by a jacket, the water is cooled by direct contact with the ambient air. Later, various additives were added to the water, which then became the coolant. The radiator was invented in 1897 by the German engineer Wilhelm Maybach. After many trial and error, he developed the so-called "honeycomb" radiator which allows very efficient cooling of a liquid. It is composed of a bundle of short and narrow conduits between which the air circulates. Air can be accelerated by a fan in front of or behind it. This radiator is located in a closed or semi-closed circuit filled with a liquid (water-based) ensuring the cooling of the engine. In the oldest engines, the circulation of water is ensured by thermo siphon: The water heated by the engine goes up to the radiator, placed in height. Once cooled, it goes down to the motor. In modern engines, a water pump is used.

Permanent temperature control aims to maintain water and oil under conditions allowing optimum lubrication. Ideally, the coolant temperature is about $80-90^{\circ} \mathrm{C}$, determined by several factors such as machining tolerances and frictional resistance of the mechanical parts, lubricants used. The regulation of this temperature is generally obtained by a thermostatic valve located in the cooling circuit, associated with one or more fans controlled by a thermo contact which closes their electrical supply circuit) set to the maximum temperature permanently tolerable by the motor. In marine engines, the radiator is replaced by a water/water heat exchanger. The external water recovers the energy from the internal coolant to the engine.

The nozzle radiator is a heat exchanger in which the air being heated generates a certain thrust. This effect is created by introducing air into the cooler through thin slots oriented in the direction of movement of the vehicle where it expands as it heats up and exits through a nozzle in the opposite direction to movement. The system generates no thrust when the vehicle is stationary. This cooling principle has been implemented on water-cooled airplanes. The patent of this device was deposited in 1915 by Hugo Junkers.

\section{Oil Cooling}

All internal combustion engines use a liquid for lubricating moving parts, the circulating oil being pressurized by a pump. It is therefore sufficient to circulate this liquid in the hottest zones and, above all, to ensure the correct cooling thereof. All use more or less the oil cooling: Oil sump low engine ventilated, sometimes equipped with fins a small radiator oil.

Examples: The 4-cylinder of the first Suzuki GSX-R bike and the flat twin of the Citroën $2 \mathrm{CV}$ use a mixed air-oil cooling, with an oil cooler.

As advantages: Pipes, pump, independent radiator and liquid, specific to the cooling become useless. This allows a clear weight gain and a greater simplicity of design.

As a disadvantage, the oil carries less heat than water and the specificities of these oils make them more expensive for the user. In addition, the lubrication of the engine is less efficient (to iso perimeter) because there are pressure losses due to circulation in the oil cooler.

\section{Maintenance}

Internal combustion engines require regular maintenance of their various components. The program is established at the time of design by the manufacturers themselves.

\section{Histories}

\section{Single Cylinder}

The first patent concerning an internal combustion engine was submitted by Switzerland's François Isaac de Rivaz on January 30, 1807. The first two-stroke engine was designed and built by Étienne Lenoir in 1860. It operates according to the Lenoir cycle. We know a device that burned powder, very close to an internal combustion engine and used to send $3000 \mathrm{~m}^{3}$ of water every day to the gardens of the Palace of Versailles under Louis XIV, designed by Christian Huygens in 1673 and Built in 1685. Around 1862, the Germans Otto and Langen, noticing the low efficiency of the twostroke engine of Lenoir (1860), undertook a series of improvements: The most decisive was to synchronize the movements in the compression phase. This engine had little to do with current engines; It was in fact an atmospheric engine, that is to say that the piston, propelled by the explosion of the gas, was in mesh and exerted a motor work on the tree only at the beginning of the Exhaust phase, the air call returning the piston to its compression position.

The company Motorenfabrik Otto and Co. founded in Cologne in 1864 gave birth in 1876 to the Deutz AG (which still exists), an agricultural equipment construction firm. Otto developed a four-stroke combustion engine that he patented in Germany. However, as a result of a right of priority invoked before the courts by Beau de Rochas, this patent was annulled in 1886. Gottlieb Daimler and Carl Benz (1886), then independently, Siegfried Marcus in Vienna from 1889, Their first tractors by operating the Otto engine. 


\section{Four Cylinders}

Panhard and Levassor, from 1896, engaged a "four cylinders in line" on the Paris-Marseille-Paris race. Two years later, multicylinders (four-cylinder) win the big cars and gradually become widespread throughout the range, becoming, in a way, the world's archetype for current cars of medium and low ranges.

A first variant, the four-cylinder $\mathrm{V}$-shaped, makes its appearance at the hinge of two centuries, on models Mors and Ader. A few years later, this solution seduced Peugeot and Ariès for their current models before 1914. Much later, from 1962, Ford will make a wide use, but also Matra and SAAB. Second variant, the four-cylinder (in-line) coated, which is found in competition with Amédée Bollée (1898/99) (first four-cylinder monoblock engine (the other four-cylinder engines at the time were twin-cylinder or single cylinder and Wolseley and Winton (1903). It was found on BMW $\mathrm{K}$ series motorcycles and on the Peugeot 104-205, but also on utility vehicles or MPVs opting for the "underfloor engine" solution. Third variant, the 4-cylinder boxer. Emblematic, in its air-cooled version, of the "ladybugs" of Volkswagen. This architecture has the great advantage of benefiting the vehicle which it motorizes from a center of gravity low enough. A tough and turbocharged version is now equipping the Subaru Impreza which are formidable competitors of the World Rally Championship WRC.

But racing-where speed is sought - is demanding in terms of power, especially when it comes to races. Hence the temptation to increase the number of cylinders.

\section{Six Cylinders}

The Dutch brand Spyker had introduced a 6-cylinder model in 1903. A Chadwick model in the United States took the plunge in 1907 for the Fairmont coastal race. The following year, this time in Europe, Rolls-Royce did the same for the London-Edinburgh race, using six cylinders. Transposition to current models is almost immediate for sports and luxury cars. In Europe, it is the case for Delaunay-Belleville, Napier, Mercedes, in the United States for Marmon (en). Later, starting in 1927, there were six cylinders (almost always in line) on a large number of non-sporty models, even for modest displacement. The main advantage of this solution is the flexibility of the engine. In the world of motorcycles, the 6-cylinder will remain rare. It is found in competition, especially at Honda in the 1960s (on-line engine) or at Laverda in endurance ( $\mathrm{V}$-engine).

Engines with more than four cylinders will be banned for a long time. On Honda CBX 1000 (air-cooled 24valve engine) the Kawasaki Z 1300 (water-cooled 12valve engine) and the Benelli 750 then 900. In 2016, Honda still offers its catalog a flat 6-cylinder model, the Gold Wing and BMW the K 1600 GT/GTL since 2011.

\section{Eight Cylinders and More}

A new step is taken when we switch to the "eight cylinders". Ader (France) opened the way in 1903 for the Paris-Madrid, with an eight-cylinder V-unit. In the same year, eight cylinders appeared in line. The aircraft engines, in search of the lowest weight for a given power, end in 1908 to the rotary engine with 5 or 7 or 9 or 11 star cylinders whose assembly rotates around a fixed crankshaft. This solution, adopted for many First World War planes, will not survive. The aircraft engines of the 1930 and 1940 s respond to the everincreasing demand for power. The current engines are V12 or star engines with one to four rows of 7 to 9 cylinders, i.e., 28 cylinders at the end of the war for the Pratt and Whitney R-4360 developing 3,500 hp or 18 for the Wright R- 3350, which equip the bomber B29 and then the first generation of transatlantic airliners, soon replaced by the reactors.

The Americans, lovers of big cars and without concern for the price of gasoline, democrazed the big V8 to the very high torque and the speeds of rotation quite slow. The manufacturers of the Formula 1 cars used for a long time 3-cylinder V8, including the famous Ford Cosworth. In the 1990s, the V10 structure will be favored by F1 engine manufacturers. Even the Ferrari team, very attached to the 12-cylinder $\mathrm{V}$, will fold the laws of this formula. Since 2006, the sports bodies (FIA) have imposed a return to the V8 with more reliability constraints than in the past. In 2006, the V-shaped structures of 10 or 12-cylinder and W16 are reserved for vehicles with strong sporting tendencies.

\section{Advantages}

Internal combustion engines are fairly light and small, compensating for a slightly low torque by a high rotational speed. Their energy source is compact and quickly "renewable", which makes them well suited to equip small vehicles but also flying. It is no longer necessary to drag a ton of coal in addition to a cistern of water to hope to advance at a reasonable speed. The ease of use and maintenance of this type of engine also explains its success. Also, these engines are not delicate and operate without problems with various fuels, without the need for major modifications. Petroleum-based gasoline is sometimes replaced by alcohol or gas and diesel by vegetable oils, which gives them an interest even in the event of a shortage of fossil fuels.

Steam engines are powerful, but terribly heavy and cumbersome. In addition, they require a long heating phase. On the other hand, they allow a very efficient start-up, thanks to the accumulated vapor pressure;

Electric motors have an excellent efficiency, but use a source of energy whose storage or production is poorly controlled: The batteries remain heavy, cumbersome and, above all, long to recharge. 
However, advances in the storage of electrical energy may allow the electric motor to supplant the internal combustion engine in the automotive field because of its many advantages.

\section{Disadvantages}

These engines are only really effective at low altitudes, where the oxygen content of the air is high. Internal combustion engines have allowed aircraft to fly, but they also limit their evolution. This disadvantage can be partially compensated by the use of compressors or turbochargers. They are unusable in media that do not contain dioxygen (submarines, extraterrestrial vehicles). Combustion results in the release of polluting gases. They are one of the main sources of air pollution in cities.

The efficiency of the internal combustion engine is rather poor compared to the electric motor its efficiency degrades very strongly outside the optimal operating range. In the case where the speed of rotation of the device must be able to vary significantly (vehicle, for example), they require the interleaving of a complex mechanical system (gearbox) making it possible to modify the rotation ratios in order to maintain the engine in Its operating range.

The torque is zero at start-up, hence the need for an auxiliary device to start the engine (crank, electric starter, etc.).

They usually use a fossil fuel, so they need an energy source that is not renewable on a human scale. Its user depends on the supply of fuel and its cost. Internal combustion engines using fossil fuels release $\mathrm{CO}_{2}$ that contributes to the greenhouse effect. The internal combustion engine requires regular maintenance (oil and water change, change of air and fuel filters, adjustments), to maintain optimal performance and maximum service life. Compared to an electric motor, they are much noisier and generate more vibrations due to the displacement of the many mechanical parts inside.

\section{Improvements}

\section{Modification of the Gas Mixture}

Among all the modifications which improve operation, mention may be made of the addition of water or steam to the gas mixture. See two links: Water motor, (in particular the water motor part: Water injection in combustion engines) and the dedicated article water injection in engines.

\section{Variable Compression Ratio}

Called Variable Compression Ratio (VCR), the efficiency improves as the compression ratio of the air/fuel mixture increases.

However, too compressed, the mixture self-ignites prematurely, causing a mechanically destructive knocking phenomenon.
One solution to this problem is to dynamically vary the compression ratio. Indeed, in cities, for example, the engine often operates at low speed far from its optimum load, with poor efficiency, which can be seen by high fuel consumption (Hence the advantage of adapting the compression ratio according to the load and the stresses).

In 1928 Louis Damblanc filed a patent for a variable compression engine. After Volkswagen in 1987, Saab introduced a patent in 1990 and tested its engine over $100,000 \mathrm{~km}$ before abandoning it because of excessive noise and vibration.

A solution proposed with the MCE-5 motor is to vary the volume of the combustion chamber by varying the height of the piston in the axis of the cylinder by means of a toothed wheel and a rack with an electronic calculation of the optimum position.

The connecting rod controlling the axis of the toothed wheel and no longer the piston makes it possible to eliminate the lateral forces on the piston and a complementary gain in efficiency.

The VCR is particularly interesting coupled with a turbocharger-its presence imposing a low compression ratio on a conventional engine - while with the VCR the compression rate will remain optimal.

Among its advantages, the VCR accepts several types of fuel (gas ...) and the exhaust gases being warmer, the catalytic converter rises faster in temperature. Problems of weight, mechanical strength and industrial cost issues must be addressed. The industrialization of a large-scale VCR engine by 20152020 remains very possible if fuel consumption or political will reduces fuel consumption as a priority. Its industrialization would be simpler than that of a hybrid vehicle (Four-stroke engine, From Wikipedia; Nikolaus Otto, From Wikipedia; Otto cycle, From Wikipedia; Otto engine, From Wikipedia).

\section{Materials and Methods}

In an internal combustion engine, with approximately one third of the total energy fuel inlet is converted to a useful.

A large part of energy shall be forfeited in the exhaust gases. In addition, another important part of the consumption of energy is rejected in the form of heat through the cooling system.

The importance of this study is to identify the key factor which contribute to the heat loss, which still can be used to minimize the heat loss and at the same time improves the power and efficiency of the mechanical components. Loss of stored energy increases with increasing the speed of the engine and the load and therefore decreases the efficiency of the mechanical components. 
An important way to reduce losses of heat engines is how to achieve a better balance.

In addition, a good balance, in order to achieve a quiet operation and long-term, without high wear, noise and vibrations.

An important way to reduce losses of heat engines is how to achieve a better balance.

On the other hand, the parties equal positive of the two forces do not give the moments, in such a way that they produce a dynamic balance (partially). In exchange only parts of the two forces which are equal, but have opposite signs, with all that cancels the forces (static), give a negative moment (load), which imbalance (partial) dynamic engine.

Solution is adopted in order to balance the total dynamics of such a motor is the doubling of the engine (in the mirror), so as to obtain an engine in line, which has a crank handle with a lag of 180 [degree], in the motor with four cylinders.

\section{Balancing an in Line Engine, Which has a Crank with a Gap of 180 [Deg]}

Internal combustion engines in-line (whether working in four-stroke or two-stroke engines-Otto, Diesel and Lenoir) are generally the most used (Antonescu et al., 2000).

Their balancing problem is extremely important for their proper functioning (Stout, 2001; Frățilă et al., 1982; 1986; Froelund et al., 2004; Grunwald, 1980; Leet et al., 2004; Marincaş et al., 1982; Pelecudi, 1985). There are two possible types of balancing: Static and dynamic (Antonescu et al., 2000; Stout, 2001; Frățilă et al., 1982; 1986; Froelund et al., 2004; Grunwald, 1980; Leet et al., 2004; Marincaș et al., 1982; Pelecudi, 1985).

Total static balancing make that the sum of the forces of inertia of a mechanism be zero. There are also and a partial static balancing (Antonescu et al., 2000; Stout, 2001; Frățilă et al., 1982; 1986; Froelund et al., 2004; Grunwald, 1980; Leet et al., 2004; Marincaș et al., 1982; Pelecudi, 1985).

Dynamic balancing means to canceling all the moments (loads) of the inertial of the mechanism (Grunwald, 1980).

One mode of design of an in line engine, is the one with the gap between cranks of 180 [deg] (Antonescu et al., 2000; Stout, 2001, Frățilă et al., 1982; 1986; Froelund et al., 2004; Grunwald, 1980; Leet et al., 2004; Marincaș et al., 1982; Pelecudi, 1985; Petrescu and Petrescu, 2003; 2005a; 2005b; 2009; 2012; Taraza, 2002).

In this type of engine (regardless of their position, which is most often vertical) for two motors cylinders, have a partial static imbalance (i.e., there is a partial static balancing) and a dynamic imbalance (Petrescu and Petrescu, 2012).

Shall I write following relations of calculation (1):

$\left\{\begin{array}{l}s_{B}=r \cdot \sin \phi_{1}+l \cdot \sin \phi_{2} ; \\ \ddot{s}_{B}=-r \cdot \sin \phi_{1} \cdot \omega_{1}^{2}-l \cdot \sin \phi_{2} \cdot \omega_{2}^{2} \\ F=F_{B}^{i}=-m_{p} \cdot \ddot{s}_{B}= \\ =m_{p} \cdot r \cdot \sin \phi_{1} \cdot \omega_{1}^{2}+m_{p} \cdot l \cdot \sin \phi_{2} \cdot \omega_{2}^{2} \\ \sin \left(\phi_{1}+\pi\right)=-\sin \phi_{1} ; \sin \phi_{2^{\prime}}=\sin \phi_{2} \\ s_{D}=r \cdot \sin \left(\phi_{1}+\pi\right)+l \cdot \sin \phi_{2^{\prime}} \\ \ddot{s}_{D}=-r \cdot \sin \left(\phi_{1}+\pi\right) \cdot \omega_{1}^{2}-l \cdot \sin \phi_{2^{\prime}} \cdot \omega_{2}^{2} \\ =r \cdot \sin \phi_{1} \cdot \omega_{1}^{2}-l \cdot \sin \phi_{2} \cdot \omega_{2}^{2} \\ F_{D}^{i}=-m_{p} \cdot \ddot{s}_{D} \\ =-m_{p} \cdot r \cdot \sin \phi_{1} \cdot \omega_{1}^{2}+m_{p} \cdot l \cdot \sin \phi_{2} \cdot \omega_{2}^{2} \\ M^{i}=a \cdot m_{p} \cdot r \cdot \sin \phi_{1} \cdot \omega_{1}^{2}\end{array}\right.$

Figure 1 shows the kinematic scheme of a such mechanism (a two-cylinder in-line engine) which has a crank with a gap of 180 [deg] (Petrescu and Petrescu, 2003; 2005a; 2005b; 2009; 2012; Taraza, 2002). Parties of the relations of forces $F_{B}^{i}$ and $F_{D}^{i}$ that are equal but have opposite signs cancel each other, producing a partial static balance of the engine.

The other two parts of expressions of forces which have the same sign, are equal and not cancel each other, but rather come together, producing a static imbalance (partial) of the engine (Petrescu and Petrescu, 2003; 2005a; 2005b; 2009; 2012; Taraza, 2002).

On the other hand positive equal parts of the two forces do not give moments, so produce a dynamic balance (partial) engine.

Instead just the parts of the two forces that are equal but have opposite signs, although it cancels the forces (static), give a negative moment (load), which unbalance (partially) dynamically the engine.

The solution adopted for the total dynamic balancing of such an engine is the engine doubling (in mirror), so as to obtain a motor in line, which has a crank with a gap of 180 [deg], in the four-cylinder engine (Fig. 2).

\section{Balancing an in Line Engine, Which has a Crank with a Gap of 120 [Deg]}

Another type of construction of the engine in line is the engine with a gap of 120 [deg].

In this type of engines (regardless of their position, which is most often vertical) for an engine in three cylinders, there is a partial static imbalance (i.e., there is a partial static balancing) and a dynamic imbalance (Petrescu and Petrescu, 2003; 2005a; 2005b; 2009; 2012; Taraza, 2002). 


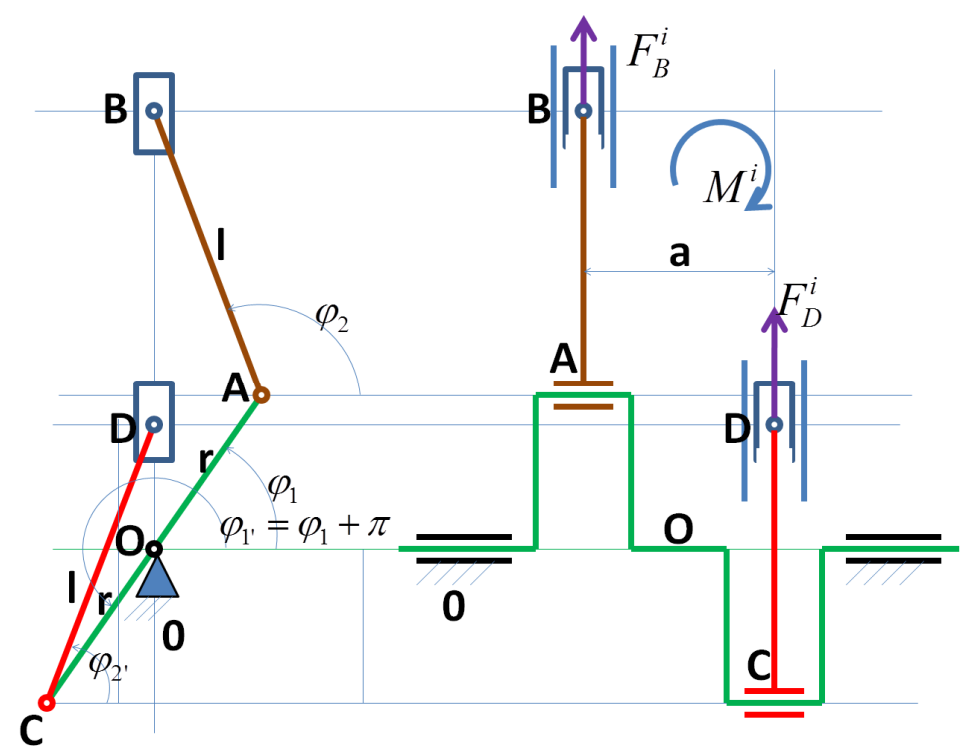

Fig. 1. Kinematic diagram of an vertical engine with two cylinders in line, which has a crank with a gap of 180 [deg]

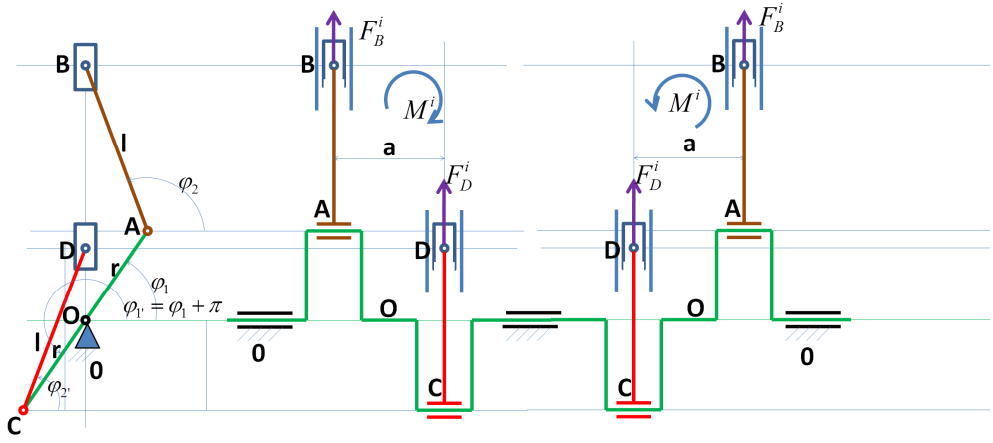

Fig. 2. Kinematic diagram of an vertical engine with four cylinders in line, which has a crank with a gap of 180 [deg]

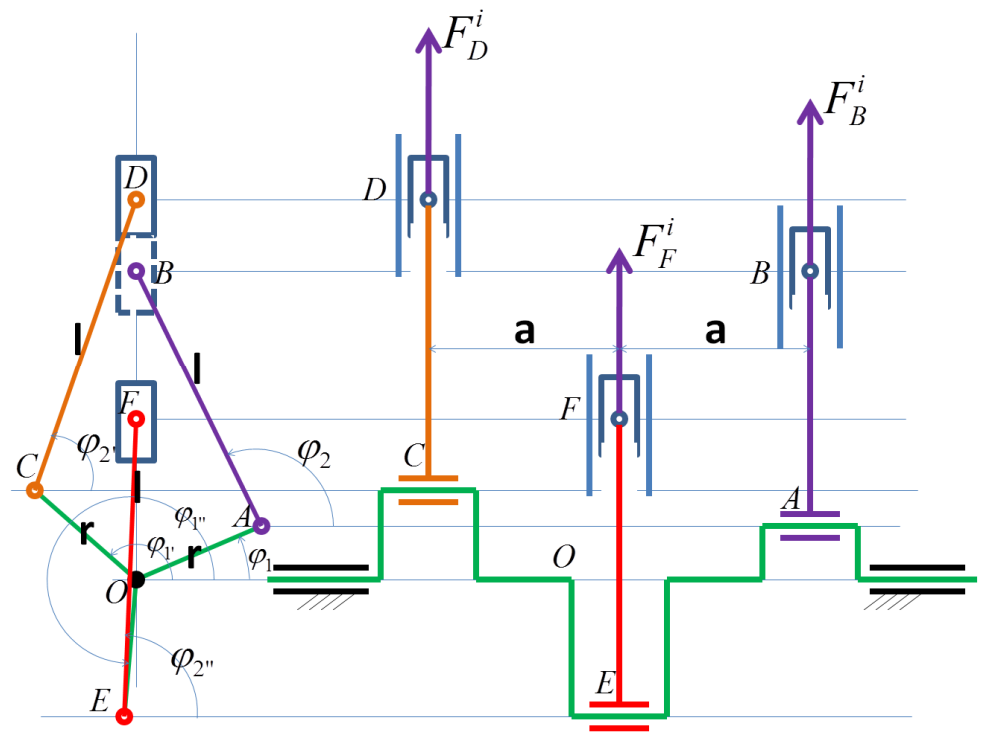

Fig. 3. Kinematic diagram of an vertical engine with three cylinders in line, which has a crank with a gap of 120 
Shall I write following relations of calculation (2):

$$
\left\{\begin{array}{l}
s_{B}=r \cdot \sin \phi_{1}+l \cdot \sin \phi_{2} ; \\
\ddot{s}_{B}=-r \cdot \sin \phi_{1} \cdot \omega_{1}^{2}-l \cdot \sin \phi_{2} \cdot \omega_{2}^{2} \\
F=F_{B}^{i}=-m_{p} \cdot \ddot{s}_{B}=m_{p} \cdot r \cdot \sin \phi_{1} \cdot \omega_{1}^{2}+m_{p} \cdot l \cdot \sin \phi_{2} \cdot \omega_{2}^{2} \\
s_{D}=r \cdot \sin \left(\phi_{1}+\frac{2 \pi}{3}\right)+l \cdot \sin \phi_{2^{\prime}} \\
\ddot{s}_{D}=-r \cdot \sin \left(\phi_{1}+\frac{2 \pi}{3}\right) \cdot \omega_{1}^{2}-l \cdot \sin \phi_{2^{\prime}} \cdot \omega_{2}^{2}=0.5 \cdot r \\
\sin \phi_{1} \cdot \omega_{1}^{2}-0.866 \cdot r \cdot \cos \phi_{1} \cdot \omega_{1}^{2}-l \cdot \sin \phi_{2^{\prime}} \cdot \omega_{2}^{2} \\
F_{D}^{i}=-m_{p} \cdot \ddot{s}_{D}=-0.5 \cdot m_{p} \cdot r \cdot \sin \phi_{1} \cdot \omega_{1}^{2} \\
+0.866 \cdot m_{p} \cdot r \cdot \cos \phi_{1} \cdot \omega_{1}^{2}+m_{p} \cdot l \cdot \sin \phi_{2^{\prime}} \cdot \omega_{2}^{2} \\
s_{F}=r \cdot \sin \left(\phi_{1}-\frac{2 \pi}{3}\right)+l \cdot \sin \phi_{2^{n}} \\
\ddot{s}_{F}=-r \cdot \sin \left(\phi_{1}-\frac{2 \pi}{3}\right) \cdot \omega_{1}^{2}-l \cdot \sin \phi_{2^{n}} \cdot \omega_{2}^{2} \\
=0.5 \cdot r \cdot \sin \phi_{1} \cdot \omega_{1}^{2}+0.866 \cdot r \cdot \cos \phi_{1} \cdot \omega_{1}^{2}-l \cdot \sin \phi_{2^{n}} \cdot \omega_{2}^{2} \\
F_{F}^{i}=-m_{p} \cdot \ddot{s}_{F}=-0.5 \cdot m_{p} \cdot r \cdot \sin \phi_{1} \cdot \omega_{1}^{2} \\
-0.866 \cdot m_{p} \cdot r \cdot \cos \phi_{1} \cdot \omega_{1}^{2}+m_{p} \cdot l \cdot \sin \phi_{2^{n}} \cdot \omega_{2}^{2}
\end{array}\right.
$$

Figure 3 shows the kinematic scheme of the mechanism of such an in-line three-cylinder engine, which has a crank with a gap of 120 [deg] (Petrescu and Petrescu, 2012).

The first component of the force $F_{B}^{i}$ is canceled by the first component of the other two forces $F_{D}^{i}$ and $F_{F}^{i}$ therefore it produces a static balance (partial), but these first components give a dynamic moment, so we have a dynamic imbalance.
A second component of the force $F_{D}^{i}$ is equal and opposite sign of the second component of the force $F_{F}^{i}$, they canceling each other and thus generating a static balancing (partial) additional, but additionally producing a dynamic moment, creating an imbalance additional dynamic.

The second component of force $F_{B}^{i}$ is added to the third component of the other two forces $F_{D}^{i}$ and $F_{F}^{i}$.

They produce a static imbalance and gives and a dynamic moment at the same time producing a dynamic imbalance (Petrescu and Petrescu, 2003; 2005a; 2005b; 2009; 2012; Taraza, 2002).

Adopting an engine solution doubled symmetrically in a mirror (a six-cylinder engine in line with a phase shift of the cranks from 120 [deg]), we achieved an overall dynamic balance (cancellation of all moments given of inertia forces) and a static balance (partial) of two-thirds of the total inertial forces, a balancing which is however superior than of the in-line engines with a phase shift of the cranks from 180 [deg] (Fig. 4), (Petrescu and Petrescu, 2003; 2005a; 2005b; 2009; 2012; Taraza, 2002).

Remarks: Similarly constructed inline engines with more cylinders, having to crank ever smaller gaps, are obtained by doubling the number of cylinders in the mirror, linear motors with a total dynamic balanced and a partial static balanced that can becoming better. Thus, to an in-line five-cylinder engine with the gap between cranks of $720 / 5=72$ [deg], one obtains a superior partial static balance and by doubling the engine symmetrically mirrored by making a linear motor with ten cylinders, one obtains a superior partial static balance and an overall dynamic balance.

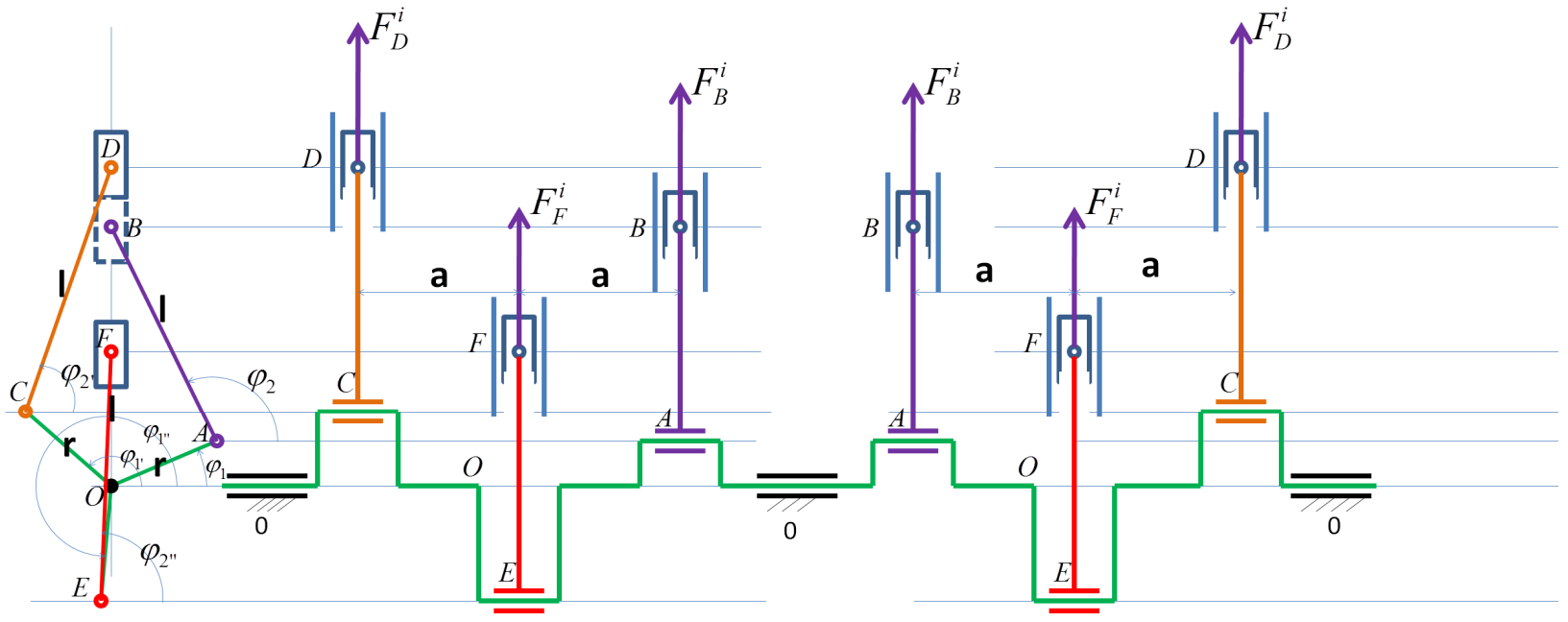

Fig. 4. Kinematic diagram of an vertical engine with six cylinders in line, which has a crank with a gap of 120 [deg] 
And so already but constructive and technological requirements then become increasingly difficult. V engines can't achieve any total static balancing, but not one overall dynamic. For an improvement in the dynamics of these higher efficiency motors, see dynamic and kinematic conditions of constructive alpha angle choice (Petrescu and Petrescu, 2003; 2005a; 2005b; 2009; 2012; Taraza, 2002). The most complete solution for balancing internal combustion heat engine is considered to be one with opposite cylinder (boxer). For two-cylinder opposed one obtains a complete static balancing (of inertia forces) and by doubling constructive symmetrical in a mirror of the number of cylinders, for a four-cylinder boxer engine, opposite two by two, one obtains and the total dynamic balancing (of the moments given by the inertial forces) together with total static balance.

\section{Balancing an Engine (in Line) with Opposed Cylinders (Boxers)}

Another type of motor construction is the engine with opposed cylinders in line, called cylinder "boxers". In this type of engine (regardless of their position, which is most often vertical) for twocylinder motor, one has a total static balancing and a dynamic imbalance. Shall I write following relations of calculation (3):

$$
\left\{\begin{array}{l}
s_{B}=r \cdot \sin \phi_{1}+l \cdot \sin \phi_{2} ; \\
\ddot{s}_{B}=-r \cdot \sin \phi_{1} \cdot \omega_{1}^{2}-l \cdot \sin \phi_{2} \cdot \omega_{2}^{2} \\
F=F_{B}^{i}=-m_{p} \cdot \ddot{s}_{B}=m_{p} \cdot r \cdot \sin \phi_{1} \cdot \omega_{1}^{2}+m_{p} \cdot l \cdot \sin \phi_{2} \cdot \omega_{2}^{2} \\
\sin \left(\phi_{1}+\pi\right)=-\sin \phi_{1} ; \\
\sin \left(\phi_{2}+\pi\right)=-\sin \phi_{2} \\
s_{D}=r \cdot \sin \left(\phi_{1}+\pi\right)+l \cdot \sin \left(\phi_{2}+\pi\right) \\
\ddot{s}_{D}=-r \cdot \sin \left(\phi_{1}+\pi\right) \cdot \omega_{1}^{2}-l \cdot \sin \left(\phi_{2}+\pi\right) \cdot \omega_{2}^{2} \\
=r \cdot \sin \phi_{1} \cdot \omega_{1}^{2}+l \cdot \sin \phi_{2} \cdot \omega_{2}^{2}=-\ddot{s}_{B} \\
F_{D}^{i}=-m_{p} \cdot \ddot{s}_{D}=m_{p} \cdot \ddot{s}_{B}=-F_{B}^{i}=-F \\
=-m_{p} \cdot r \cdot \sin \phi_{1} \cdot \omega_{1}^{2}-m_{p} \cdot l \cdot \sin \phi_{2} \cdot \omega_{2}^{2} \\
F_{D}^{i}+F_{B}^{i}=0 \text { dar } M^{i} \neq 0 \\
M^{i}=a \cdot F_{B}^{i}=-a \cdot m_{p} \cdot \ddot{s}_{B} \Rightarrow \\
\Rightarrow M^{i}=a \cdot m_{p} \cdot r \cdot \sin \phi_{1} \cdot \omega_{1}^{2}+a \cdot m_{p} \cdot l \cdot \sin \phi_{2} \cdot \omega_{2}^{2} \\
\text { At the Engine doubled in a mirror } \\
\sum F^{i}=0 \\
\sum M^{i}=0
\end{array}\right.
$$

Figure 5 shows the kinematic scheme of the mechanism of a such an engine (with two opposite cylinders, in line) (boxers) (Petrescu and Petrescu, 2003; 2005a; 2005b; 2009; 2012; Taraza, 2002).
This two-cylinder boxer engine is statically balanced total (the sum of the forces of inertia is to be canceled).

He is just unbalanced dynamic (has a inertial moment which is different from zero), but can be balanced dynamically by adding two more cylinders (by symmetrization in a mirror) boxers (Fig. 6), (Petrescu and Petrescu, 2003; 2005a; 2005b; 2009; 2012; Taraza, 2002).

Although it seems to have a higher gauge, though only in four cylinders (two opposite pairs) this type of internal combustion engine heat is almost totally balanced both statically and dynamically. The first engineer who has patented a boxer engine, was Karl Benz, who presented such a patent of a boxer engine (Fig. 7) in 1896.

In 1923 Max Friz designed and built a BMW boxer engine of $500 \mathrm{cc}$, which is still produced and used today because of its power, its low consumption and especially static and dynamic balancing total, (Petrescu and Petrescu, 2003; 2005a; 2005b; 2009; 2012; Taraza, 2002). Also has used boxer engines, the German Concern Volkswagen, obviously German group BMW, the French Citroen, Chevrolet division of American Concern GM (division created in America Swiss Louis Chevrolet 30-May-1911 together with William Durant, the owner company of the corporation Buick general Motors), Lancia and Ferrari divisions within the Italian Concern Fiat, Honda and Subaru Japanese conglomerates and former German Corporation Porsche, which is actually a major division within the German megaconcern VW.

An other engine with the total static and dynamic balancing, somewhat similar of Boxer, is the heat internal combustion engine with opposed pistons (Fig. 8).

\section{Balancing of the Rotating Concentrated Masses}

Another type of balancing is that of the concentrated masses in rotation (Antonescu et al., 2000).

The motor shafts (of the heat engines) are balancing after this model.

It is considered more (concentrated) masses, attached to a rotating shaft.

Weights are rotated together with the shaft. Can be point masses, spheres, etc, however we will consider some spheres (each of which having concentrated mass in the center of gravity) as shown in Fig. 9 (Petrescu and Petrescu, 2003; 2005a; 2005b; 2009; 2012; Taraza, 2002).

Weights are attached to the moving shaft for rotation by various supports, but will only consider the theory of the distances from the center of each sphere to the axis of the shaft. The points that fall perpendiculars passing from the center of each sphere to the axis of the shaft are marked with $1,2,3, \ldots i, \ldots \mathrm{n}$ (Antonescu et al., 2000). 


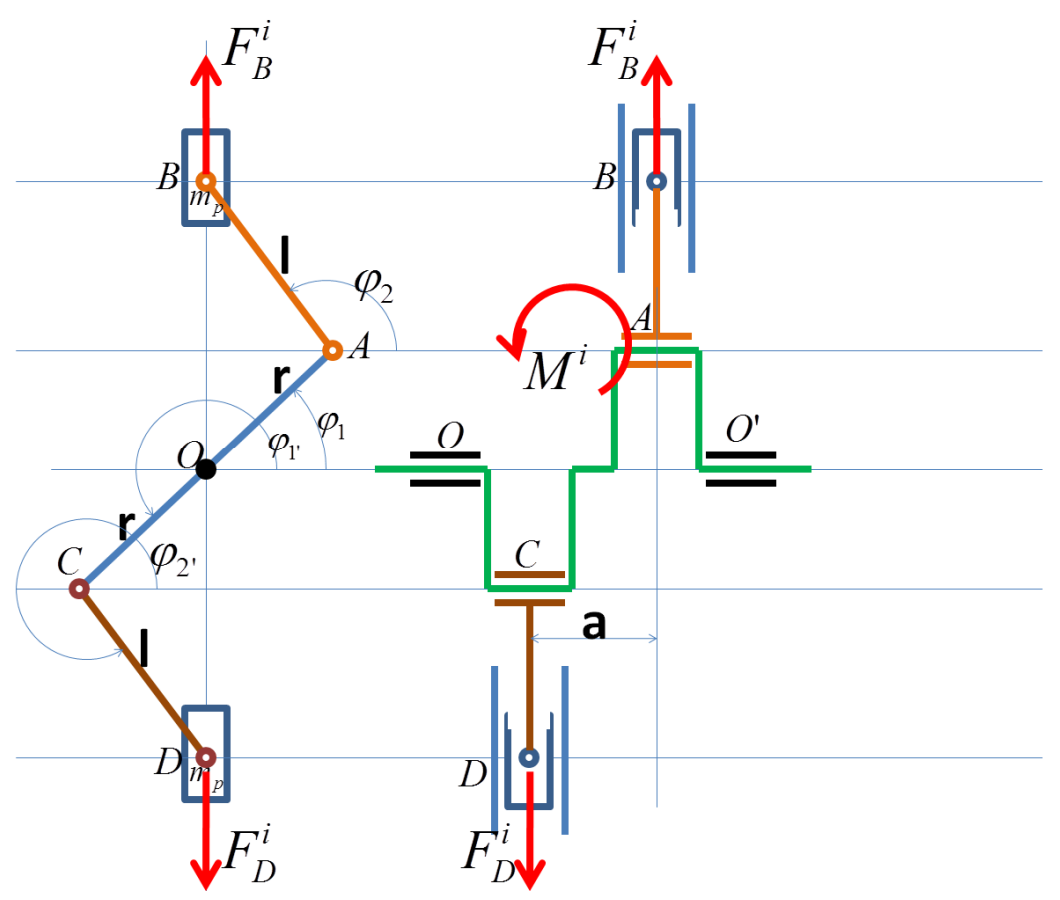

Fig. 5. Kinematic diagram of an engine in line with two opposed cylinders (boxers)

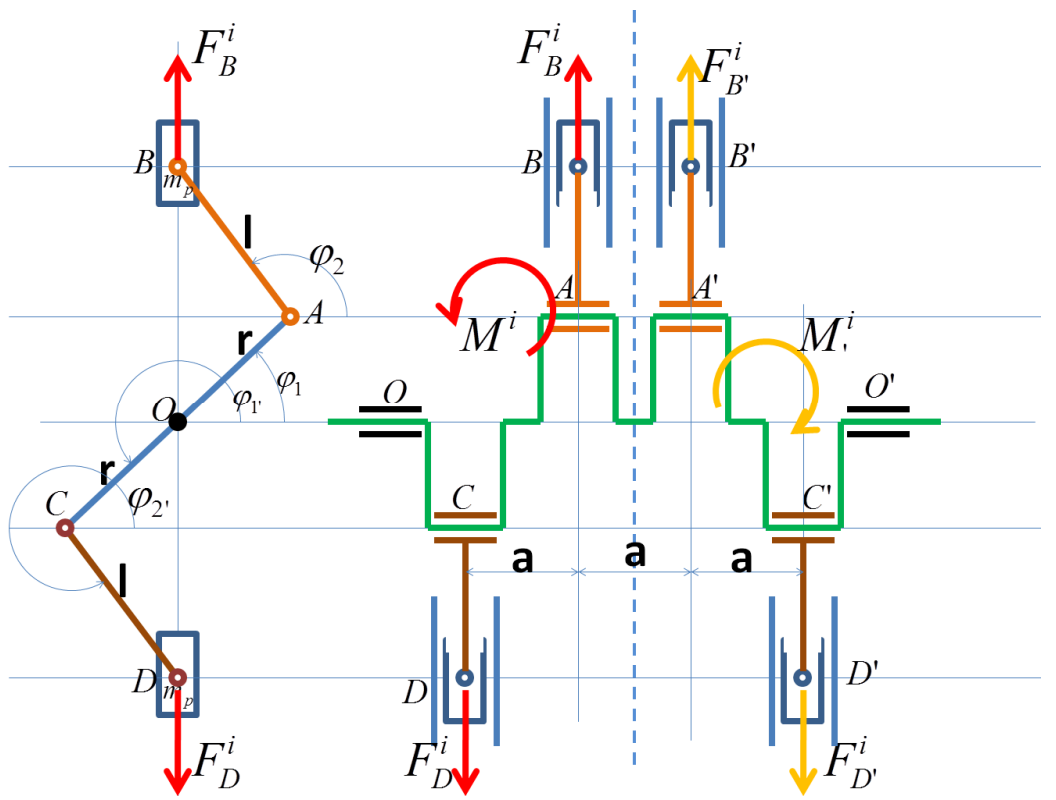

Fig. 6. Kinematic diagram of an engine in line with four opposed cylinders (boxers)

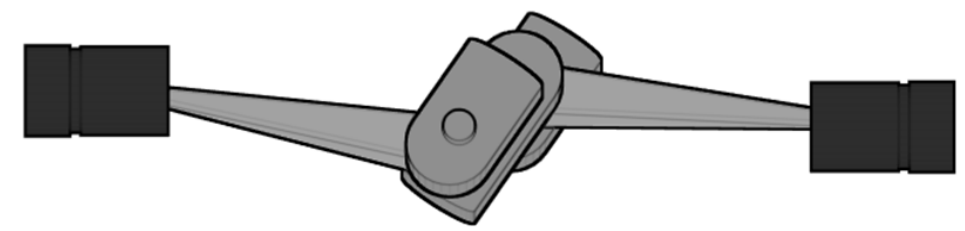

Fig. 7. First boxer engine, patented by Karl Benz 


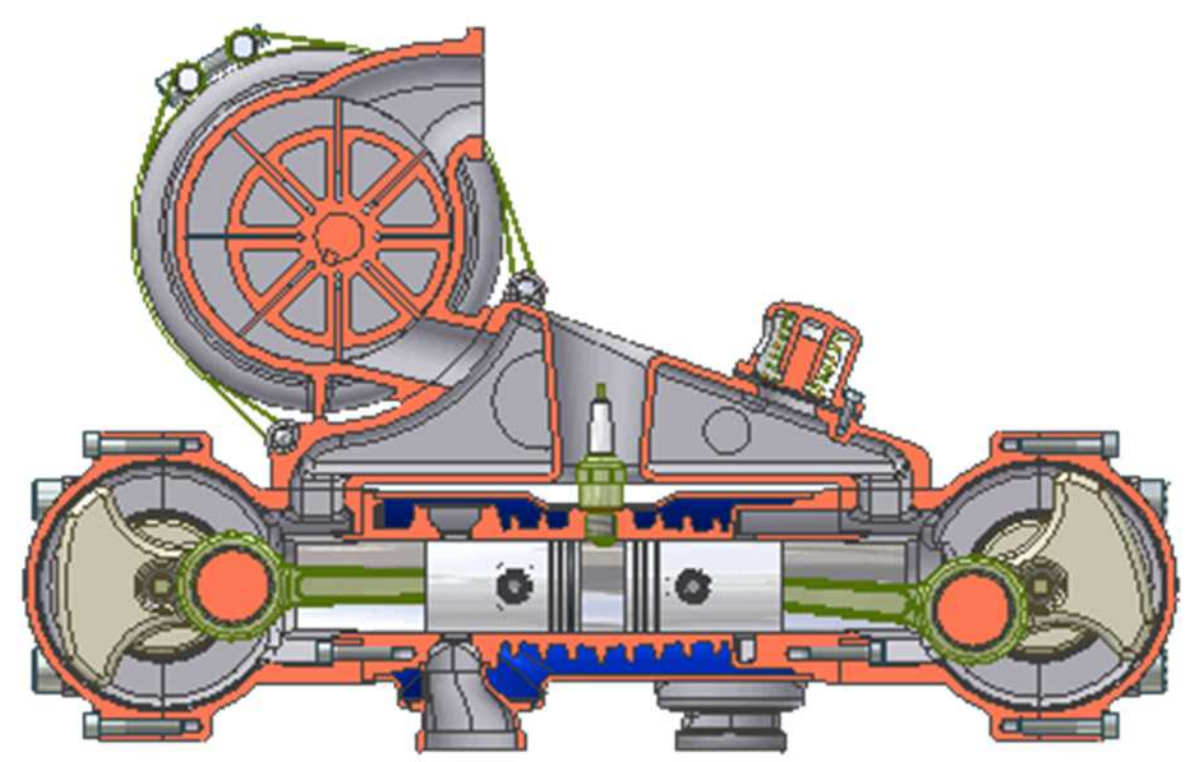

Fig. 8. Kinematic diagram of an engine in line with opposed pistons

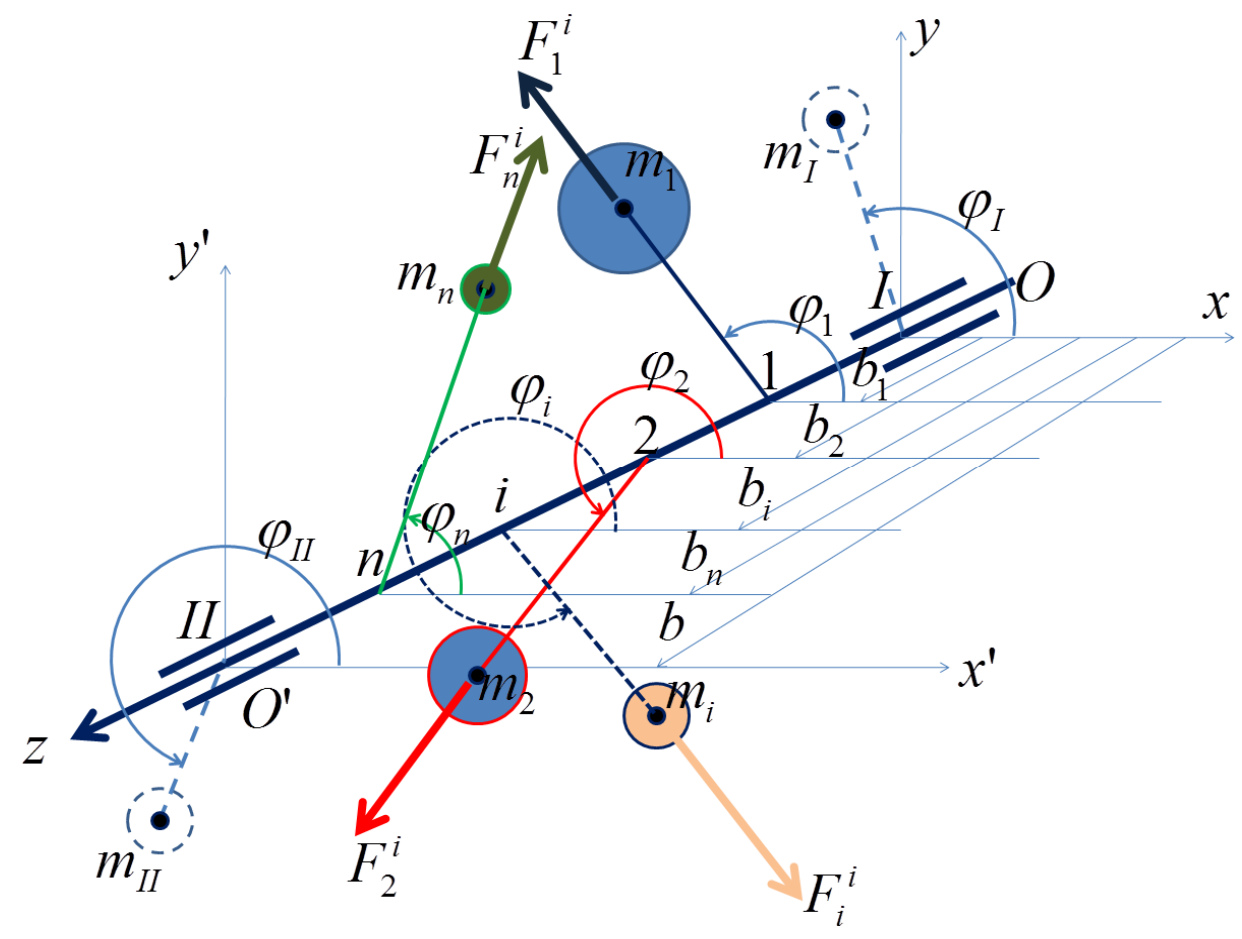

Fig. 9. Balancing of the rotating concentrated masses

Through these legs, we pulled parallel lines to the $\mathrm{x}$-axis, from which are measured the angles between distances and the horizontal axes. Is measured and the distances of these points measured on the axis of rotation from the origin $\mathrm{O}$ of the Cartesian system xOyz (Fig. 9), (Petrescu and Petrescu, 2003; 2005a; 2005b; 2009; 2012; Taraza, 2002). Shall be written the amounts moments generated by the forces of inertia of the concentrated masses in relation to the axs Ox, Oy, O'x' and O'y' (system 4). Solve system (4) is carried out with the formulae given by the system (5): 


$$
\begin{aligned}
& \left(\sum_{j=1}^{n}\left(F_{j}^{i} \cdot b_{j} \cdot \sin \phi_{j}\right)\right. \\
& +F_{I I}^{i} \cdot b \cdot \sin \phi_{I I}=0 \\
& \sum_{j=1}^{n}\left(F_{j}^{i} \cdot b_{j} \cdot \cos \phi_{j}\right) \\
& +F_{I I}^{i} \cdot b \cdot \cos \phi_{I I}=0 \\
& \sum_{j=1}^{n}\left[F_{j}^{i} \cdot\left(b-b_{j}\right) \cdot \sin \phi_{j}\right] \\
& +F_{I}^{i} \cdot b \cdot \sin \phi_{I}=0 \\
& \sum_{j=1}^{n}\left[F_{j}^{i} \cdot\left(b-b_{j}\right) \cdot \cos \phi_{j}\right] \\
& +F_{I}^{i} \cdot b \cdot \cos \phi_{I}=0 \\
& F_{I}^{i}=\frac{1}{b} \cdot \sqrt{\left\{\sum_{j=1}^{n}\left[F_{j}^{i}\left(b-b_{j}\right) \sin \phi_{j}\right]\right\}^{2}+\left\{\sum_{j=1}^{n}\left[F_{j}^{i}\left(b-b_{j}\right) \cos \phi_{j}\right]\right\}^{2}} \\
& F_{I I}^{i}=\frac{1}{b} \cdot \sqrt{\left[\sum_{j=1}^{n}\left(F_{j}^{i} \cdot b_{j} \cdot \sin \phi_{j}\right)\right]^{2}+\left[\sum_{j=1}^{n}\left(F_{j}^{i} \cdot b_{j} \cdot \cos \phi_{j}\right)\right]^{2}} \\
& \sin \phi_{I}=-\frac{\sum_{j=1}^{n}\left[F_{j}^{i} \cdot\left(b-b_{j}\right) \cdot \sin \phi_{j}\right]}{F_{I}^{i} \cdot b} ; \\
& \left\{\cos \phi_{I}=-\frac{\sum_{j=1}^{n}\left[F_{j}^{i} \cdot\left(b-b_{j}\right) \cdot \cos \phi_{j}\right]}{F_{I}^{i} \cdot b}\right. \\
& \phi_{I}=\operatorname{semn}\left(\sin \phi_{I}\right) \cdot \arccos \left(\cos \phi_{I}\right) \\
& \sin \phi_{I I}=-\frac{\sum_{j=1}^{n}\left(F_{j}^{i} \cdot b_{j} \cdot \sin \phi_{j}\right)}{F_{I I}^{i} \cdot b} ; \\
& \begin{array}{c}
\cos \phi_{I I}=-\frac{\sum_{j=1}^{n}\left(F_{j}^{i} \cdot b_{j} \cdot \cos \phi_{j}\right)}{F_{I I}^{i} \cdot b} \\
\phi_{I I}=\operatorname{semn}\left(\sin \phi_{I I}\right) \cdot \arccos \left(\cos \phi_{I I}\right)
\end{array}
\end{aligned}
$$

Similar to the model of masses concentrated in rotary motion, are solved and the balancing of the rotating shafts (Petrescu and Petrescu, 2003; 2005a; 2005b; 2009; 2012; Taraza, 2002).

\section{Results and Discussion}

\section{Presenting a New Constructive Scheme}

One presents a new and original scheme constructive debate of an internal combustion engine four-cylinder in line, by which the balancing the engine is optimally (Fig. 10).

The new scheme constructive presented has the advantages very large that it can make an economic engine, powerful, compact, quiet, which to work with limited noxious.
For a shift of balance from top, the constructive scheme (Fig. 10) may be doubled in the mirror so that we get an internal combustion engine in line, eightcylinder (Fig. 11). An important way to reduce losses of heat engines is how to achieve a better balance.

On the other hand, the parties equal positive of the two forces do not give the moments, in such a way that they produce a dynamic balance (partially). In exchange only parts of the two forces which are equal, but have opposite signs, with all that cancels the forces (static), give a negative moment (load), which imbalance (partial) dynamic engine.

Solution is adopted in order to balance the total dynamics of such a motor is the doubling of the engine (in the mirror), so as to obtain an engine in line, which has a crank handle with a lag of 180 [degree], in the motor with four cylinders.

The adoption of a dual motor symmetrically in a mirror (an engine with six cylinders in line with a change of phase of the quadrant from $120\left[^{\circ}\right]$ ), we have made a dynamic balance (the cancellation of all the data moments verification of inertias) and static balance (partial) of two thirds of the total inertia, a balance weights, yet which is higher than that of the engines in line with a change of phase of the quadrant of $180\left[^{\circ}\right]$.

Built in a similar manner, engines with more cylinders in line, having regard to crank gaps in what smaller, are obtained by doubling the number of cylinders in the mirror, linear engines, with a total dynamic balanced and a partially balance static, which may become better.

Thus, in an engine with five cylinders in line with the difference between the crank $720 / 5=72\left[^{\circ}\right.$ ], to obtain a static balance partially superior and by doubling the engine reflected symmetrically to make a linear motor with ten cylinders; to obtain a static balance the upper part and a dynamic balance to the assembly.

And so already but the requirements of construction technology and then become increasingly harder.

The V can not be performed no static balance in total, but not a dynamic overview. To improve the dynamics of these engines of greater efficiency, see the dynamic conditions and cinematic constructive alpha angle choice (Petrescu and Petrescu, 2009; 2012).

The solution the most complete for balancing the heat engine with internal combustion is considered to be one with the opposite cylinder (boxer). For the two cylinders is opposite to obtain a static full (balance of forces of inertia) and by doubling the constructive symmetrical in the mirror of the number of cylinders, for an engine boxer with four cylinders, opposing two by two, we obtain and dynamics of the total amount of load balancing (a data moments of the forces of inertia), together with a balance of the total static, but in this study the authors present a new solution and original (Fig. 11) for balancing a Otto cycle engine cylinders eight line. 


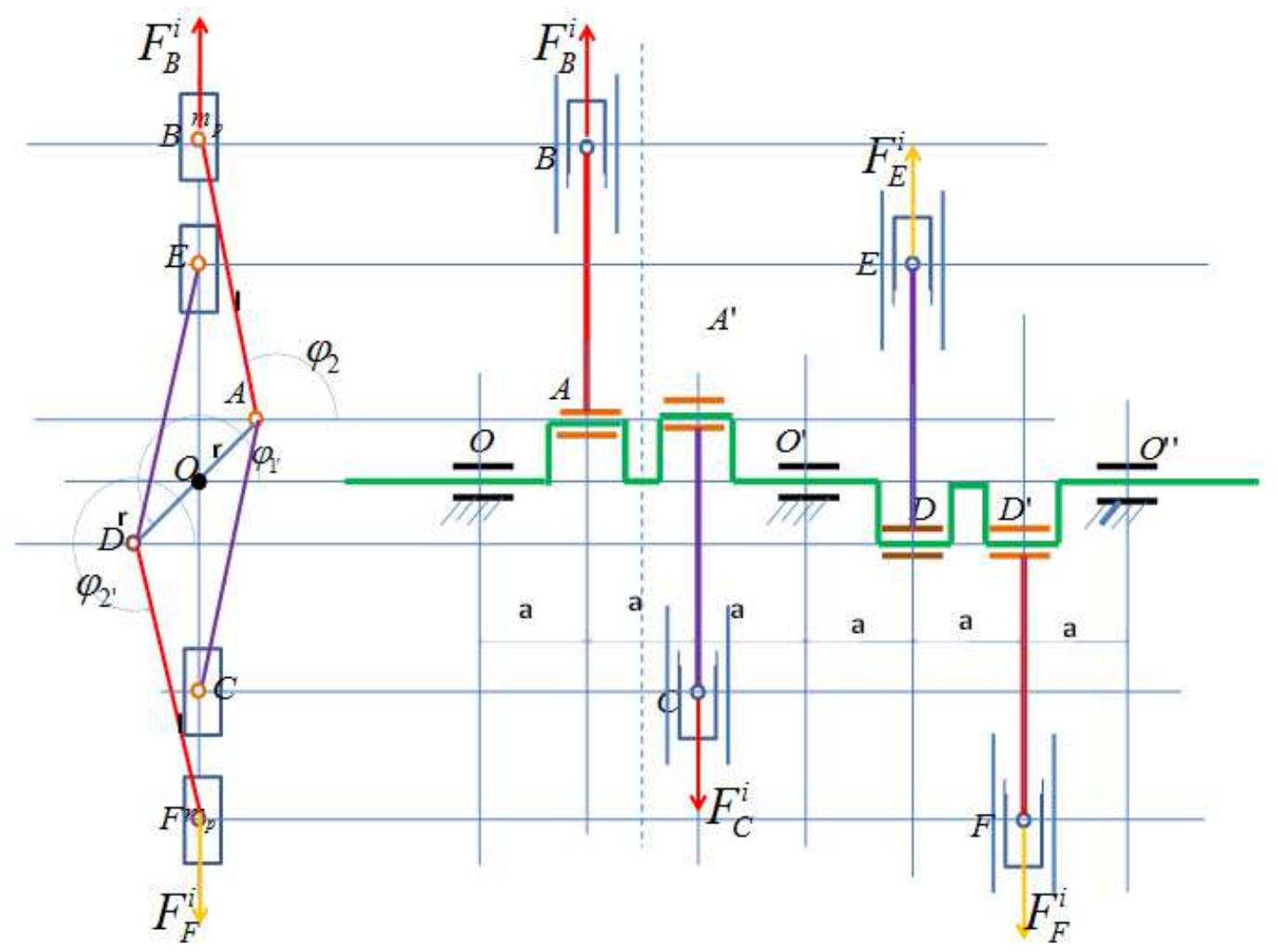

Fig. 10. Balancing of one original internal combustion engine four-cylinder in line

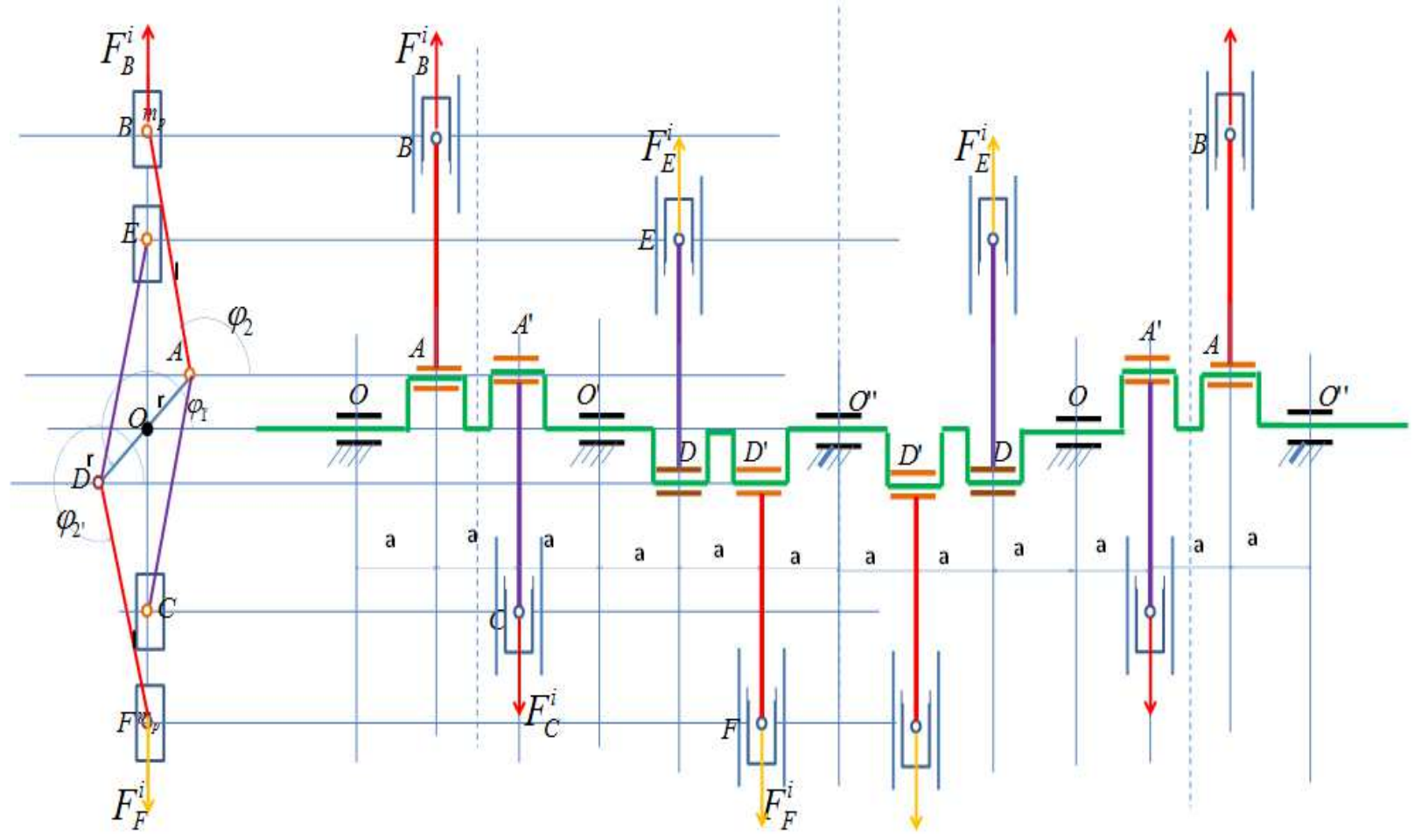

Fig. 11. Balancing of one original internal combustion engine eight-cylinder in line 


\section{Conclusion}

The term "combustion and explosion engine" refers to any type of internal combustion engine with reciprocating or rotary, diesel or spark-ignition internal combustion engines in which gases burn with a flame front whose speed is normally lower than that of sound.

This engine is mainly used for the propulsion of transport vehicles (such as airplanes, cars, motorcycles, trucks, boats) but also for many mobile tools such as chainsaws, lawn mowers and many fixed installations, Pumps, etc.).

An explosion or detonation is a particular form of combustion in which the velocity of the flame front is at least partly supersonic. In spark-ignition engines, detonation is a malfunction (rattling), normally it is a deflagration that occurs within these engines.

Internal combustion engines in line (regardless of whether the work in four-stroke engines and twostroke engines Otto cycle engines, diesel and Lenoir) are, in general, the most used. Their problem of balancing is extremely important for their operation is correct. There are two possible types of balancing: Static and dynamic balance.

The total static to make sure that the sum of the forces of inertia of a mechanism to be zero. There are also a static balance partial. Dynamic balance means to cancel all the moments (load) inertia of the mechanism. A way of the design of an engine in a straight line is that the difference between the crank $180\left[^{\circ}\right]$ or $120\left[^{\circ}\right]$.

A different type of construction of the engine is the engine with the cylinders in the opposite line, called "cylinder sportsmen".

In this type of engine (regardless of their position, which is most often vertical) for engines with two cylinders, one has a static balance total and an imbalance in the dynamic. Similar to the model of the earth concentrated in rotation movement are resolved and load balancing shafts rotating parts. An important way to reduce losses of heat engines is how to achieve a better balance.

The methods may be used in equal measure and on engines with external combustion, type Stirling or Watt.

One presents a new and original scheme constructive debate of an internal combustion engine four-cylinder in line, by which the balancing the engine is optimally (Fig. 10).

The new scheme constructive presented has the advantages very large that it can make an economic engine, powerful, compact, quiet, which to work with limited noxious.

For a shift of balance from top, the constructive scheme (Fig. 10) may be doubled in the mirror so that we get an internal combustion engine in line, eightcylinder (Fig. 11). An important way to reduce losses of heat engines is how to achieve a better balance.

\section{Acknowledgement}

This text was acknowledged and appreciated by Assoc. Pro. Taher M. Abu-Lebdeh, North Carolina A and $\mathrm{T}$ State Univesity, United States, Samuel P. Kozaitis, Professor and Department Head at Electrical and Computer Engineering, Florida Institute of Technology, United States.

\section{Funding Information}

Research contract: Contract number 36-5-4D/1986 from 24IV1985, beneficiary CNST RO (Romanian National Center for Science and Technology) Improving dynamic mechanisms internal combustion engines. All these matters are Copyrighted. Copyright 398-tDGpbsxgrD.

\section{Author's Contributions}

All the authors contributed equally to prepare, develop and carry out this manuscript.

\section{Ethics}

This article is original and contains unpublished material. Authors declare that are not ethical issues and no conflict of interest that may arise after the publication of this manuscript.

\section{References}

Antonescu, P., F. Petrescu and O. Antonescu, 2000. Contributions to the synthesis of the rotary disc-cam profile. Proceedings of the 8th International Conference on the Theory of Machines and Mechanisms, (TMM' 00), Liberec, Czech Republic, pp: 51-56.

Four-stroke engine, From Wikipedia, the free encyclopedia. Retrieved from:

Frățilă, G., D. Marincaș, N. Bejan, M. Frățilă and F. Petrescu et al., 1986. Contributions a l'amelioration de la suspension du groupe moteurtransmission. Buletinul Universităţii din Braşov, Seria A, Mecanică aplicată, 28: 117-123.

Frățilă, G., D. Sotir, F. Petrescu and V. Petrescu, 1982. Cercetări privind transmisibilitatea vibraţiilor motorului la cadrul şi caroseria automobilului. Proceedings of the 4th Conferinţă de Motoare, Automobile, Tractoare şi Maşini Agricole, (TMA' 82), CONAT-Matma, Braşov, pp: 379-388.

Froelund, K., S.C. Fritz and B. Smith, 2004. Ranking lubricating oil consumption of different power assemblies on an EMD 16-645E locomotive diesel engine. Proceedings of the CIMAC Conference, (CIMAC' 04), Kyoto, Japan. 
Grunwald, B., 1980. Teoria, Calculul şi Construcţia Motoarelor Pentru Autovehicule Rutiere. Editura didacticã şi pedagogică, Bucureşti.

Leet, J.A., S. Simescu, K. Froelund, L.G. Dodge and C.E. Roberts Jr., 2004. Emissions solutions for 2007 and 2010 heavy-duty diesel engines. Proceedings of the SAE World Congress and Exhibition, (WCE' 07), SAE, Detroit, Michigan.

Marincaș, D., D. Sotir, F. Petrescu and V. Petrescu 1982. Rezultate experimentale privind îmbunătăţirea izolaţiei fonice a cabinei autoutilitarei TV-14. În a IV-a Conferinţă de Motoare. Automobile, Tractoare şi Maşini Agricole, CONAT-matma, Braşov, 1: 389-398.

Nikolaus Otto, From Wikipedia, the free encyclopedia. https://en.wikipedia.org/wiki/Nikolaus_Otto

Otto cycle, From Wikipedia, the free encyclopedia. https://en.wikipedia.org/wiki/Otto_cycle

Otto engine, From Wikipedia, the free encyclopedia. https://en.wikipedia.org/wiki/Otto_engine

Pelecudi, C., 1985. Mecanisme. Editura Didactică şi Pedagogică, Bucureşti.

Petrescu, F.I. and R.V. Petrescu, 2003. Câteva elemente privind îmbunătăţirea designului mecanismului motor. Proceedings of 8th National Symposium on GTD, (GTD’ 03), Brasov, pp: 353-358.
Petrescu, F.I. and R.V. Petrescu, 2005a. An original internal combustion engine. Proceedings of the 9th International Symposium, (SYROM' 05), Bucharest, pp: 135-140.

Petrescu, F.I. and R.V. Petrescu, 2005b. Determining the mechanical efficiency of Otto engine's mechanism. Proceedings of the International Symposium, (SYROM' 05), Bucharest, pp: 141-146.

Petrescu, F.I. and R.V. Petrescu, 2009. V engine design. Proceedings of the International Conference on Engineering Graphics and Design, (CGD’ 09), Cluj-Napoca.

Petrescu, F.I. and R.V. Petrescu, 2012. Echilibrarea Motoarelor Termice. Create Space Publisher, USA, ISBN-10: 978-1-4811-2948-0, pp: 40.

Stout, F.L., 2001. Engine excitation decomposition methods and $\mathrm{V}$ engine results. Proceedings of the SAE Noise and Vibration Conference and Exposition, (VCE' 01), USA.

Taraza, D., 2002. Accuracy limits of IMEP determination from crankshaft speed measurements. SAE Trans. J. Eng., 111: 689-697. 